IZA DP No. 9213

Left Behind, At Risk, and Vulnerable Elders in Rural China:

What the RUMIC Data Reveal about the Extent,

Causes, and Consequences of Being Left Behind

Rachel Connelly

Margaret Maurer-Fazio

July 2015 


\title{
Left Behind, At Risk, and Vulnerable Elders in Rural China: What the RUMIC Data Reveal about the Extent, Causes, and Consequences of Being Left Behind
}

\author{
Rachel Connelly \\ Bowdoin College and IZA \\ Margaret Maurer-Fazio \\ Bates College and IZA \\ Discussion Paper No. 9213 \\ July 2015 \\ IZA \\ P.O. Box 7240 \\ 53072 Bonn \\ Germany \\ Phone: +49-228-3894-0 \\ Fax: +49-228-3894-180 \\ E-mail: iza@iza.org
}

\begin{abstract}
Any opinions expressed here are those of the author(s) and not those of IZA. Research published in this series may include views on policy, but the institute itself takes no institutional policy positions. The IZA research network is committed to the IZA Guiding Principles of Research Integrity.

The Institute for the Study of Labor (IZA) in Bonn is a local and virtual international research center and a place of communication between science, politics and business. IZA is an independent nonprofit organization supported by Deutsche Post Foundation. The center is associated with the University of Bonn and offers a stimulating research environment through its international network, workshops and conferences, data service, project support, research visits and doctoral program. IZA engages in (i) original and internationally competitive research in all fields of labor economics, (ii) development of policy concepts, and (iii) dissemination of research results and concepts to the interested public.
\end{abstract}

IZA Discussion Papers often represent preliminary work and are circulated to encourage discussion. Citation of such a paper should account for its provisional character. A revised version may be available directly from the author. 


\section{ABSTRACT \\ Left Behind, At Risk, and Vulnerable Elders in Rural China: \\ What the RUMIC Data Reveal about the Extent, Causes, and Consequences of Being Left Behind}

Migration of any distance separates family members for long periods of time. In China, an institutional legacy continues to privilege the migration of working-age individuals who often leave children and elders behind in the rural areas. Up to now, the literature has treated children and elders analogously, labeling each group "left-behind". We argue that analysis of elder stayers needs to be more nuanced, distinguishing among differing groups of elders. Of these groups, those living alone without any adult children in the village are most at risk of negative consequences of migration, while those living with other non-migrant children are much less affected by migration. We find evidence, when focusing on the consequences of migration on elders, that an elder-centric analysis is preferable to a migrant-child-centric analysis.

JEL Classification: J12, J14, J21, J26, 053

Keywords: living arrangements, aging, China, rural, elderly, left behind, at risk, migration

Corresponding author:

Margaret Maurer-Fazio

Bates College

276 Pettengill Hall

4 Andrews Road

Lewiston, Maine 04240

USA

E-mail: mmaurer@bates.edu 
What the RUMIC Data Reveal about the Extent, Causes and Consequences of Left Behind, At Risk, and Vulnerable Elders in Rural China

\section{I: Introduction and Context}

There is an increasing trend in the share of China's rural elders living alone or with spouses only. We explore, using the Rural Urban Migrants in China (RUMiC) rural data set, the extent to which the out-migration of elders' adult children contributes to this trend. We argue that no accurate accounting of "left-behind" elders can be made without first adjusting household rosters to exclude their migrant members. In addition, we draw important distinctions between migrantcentric measures and elder-centric measures of the "left behind" and vulnerable elders and urge the adoption of elder-centric measures. The majority of elders with migrant adult children still live in two- and three-generation households. Aging, widowhood and being unable to work increase the likelihood that elders live with their children. Having more sons reduces the likelihood but having more sons living in the same village increases the likelihood such that the net effect of having more sons in the village is positive. The effect of daughters is quite muted. We also combine data on elders' living arrangements and the residential locations of their adult children to derive more detailed taxonomies of their living situations. The elders who appear most at risk are those who live alone with no children residing in their village. However, this group constitutes a very small share of all the elders. A much larger share of elders live with their spouse only. In some cases they are registered as such, that is, as living with their spouse alone, but in other cases they find themselves in this situation because of the migration of offspring who are registered as household members. Although those living with their spouse only, without any children in the village, are potentially vulnerable, they also are more likely to be working and to express positive feelings of wellbeing than those living alone. Another group at risk from migration consists of elders who are caring for their grandchildren when the grandchildren's parents are migrants. These elders have high rates of employment and a more negative outlook on life than those living with their children and spouse, but not more negative than those living with children and no spouse. Overall, the loss of a spouse appears to have a larger impact of self-reported wellbeing than living arrangements vis-à-vis adult children.

In the 1950s, the Chinese leaderships adopted an economic growth strategy that emphasized the development of heavy industry. To pursue this economic development strategy while financially maintaining its generous urban social welfare system, the Chinese leadership almost completely prohibited rural to urban migration by means of a household hukou registration system that continues to the present and classifies individuals according to both residential locale and designated economic status (Chan and Zhang 1999; Fan 1999).

In the socialist period, prior to the implementation of urban economic reforms, the hukou system, in conjunction with the food rationing coupons, effectively kept rural people restricted to living and working where they were born (Meng and Manning 2010). The restrictions on migration and the hukou system were relaxed gradually, starting in the mid-1980s when the leadership eased its stance on private enterprise and entrepreneurship. In the early 1990s with both the abolishment of urban food coupons and the growth of the manufacturing sector with its concomitant increase 
in the demand for labor, the flows of migrants from rural to urban areas gained momentum. Over the most recent three decades, between 200 and 250 million rural residents moved to China's towns and cities (Chan 2012). Rural migrant labor is both an integral, enabling, factor in the success of China's low-cost manufacturing industries and the mainstay of the low-end service sector. Despite the relaxation of many of the historical restrictions on migration, the legacy of those constraints continues to severely restrict family migration and privileges the temporary migration of younger, healthy, workers who can leave their family members (parents, children, and often spouses) behind. Other institutional systems such as the health care delivery and payment system, the admissions process to universities, and agricultural land tenure rules also contribute to the social and demographic nature of China's migrant flow, coloring its landscape. Each of these institutions similarly stack the deck in favor of a pattern of the temporary migration of the prime working-age population only, leaving children to attend school in rural areas and older adults to farm, supervise children and care for elderly parents. While this strategy has allowed migrants to work long days and weeks unencumbered by day-to-day family responsibilities, it also generates very high costs in the loss of utility the prime-age adults would have gained from family interactions. Costs are also born by the children and older adults who remain in the rural areas in terms of the loss of the utility of familial interaction as well as the work of caregiving, home production, and the agricultural labor of the absent prime-age generation.

This situation is exacerbated of late by the increased length of the stays that Chinese labor migrants spend away from their homes. When the labor migration flows began in the late 1980s and early 1990s the durations were short, typically three to six months (Hare 1999). But the increasing sophistication of industrial jobs, the increasing numbers of married women migrating, the long distances traveled by migrants, and ever increasing demand for migrant labor in the growing urban service sector has increased the duration to many years away with home visits only once a year or even once every other year during Spring Festival (Connelly, Roberts, and Zheng, 2011; Liang 2007) This migration of unaccompanied prime-age adults has resulted in both a generation of migrants' children growing up with long absences of parents and growing concerns about the burdens borne by elders whose responsibilities have increased while their support systems have dwindled.

In the 2000s and 2010s, social policy researchers interested in Chinese migration turned their gaze back to the rural areas to consider the costs and benefits of migration on those family members remaining in the rural areas. (Roberts et al 2004; Biao, 2007; Giles, Wang and Zhao, 2010; Mu and Van de Walle, 2011; Connelly, Maurer-Fazio, and Zhang, 2014; Wang 2014; Tse 2015; Ao, Jiang and Zhao 2015). Remittances increase the disposable income of family members of migrants. These remittances are used to pay education fees, to build nicer houses, to pay health care costs, and buy labor-saving devices for both home and agricultural production. All of these things have contributed positively to the wellbeing of rural family members of migrants (Zhu and Luo, 2008, Biavaschi, Giulietti, and Zimmermann, 2013). On the cost side, researchers have examined school performance, children's physical and mental health, and elders' physical and mental health including feelings of loneliness (Du et al, 2004; Liang and Chen, 2007; Liang, Guo, and Duan, 2008; and Silverstein, 2008; Guo, Aranda, and Silverstein, 2009; Kong and Meng, 2010; Gao et al, 2010; Chang, Dong, and MacPhail, 2011; Chen and Powell, 2012; Jacka, 2012; Liang and Wu, 2014; Ao, Jiang and Zhao, 2015). The empirical 
analyses of the net costs and benefits of adult migration for both children and elders who remain in the rural areas are mixed. Some studies find overall negative effects and others find no significant negative effects.

This paper focuses on the "left-behind" elders. One reason it is difficult to make generalizations from the literature on "left-behind" elders is that the definitions of "left-behind" and the age groups being analyzed differ widely from study to study. Our first task is thus to explore potential definitions of "left-behind." As we demonstrate, the extent of the "problem" of "leftbehind" elders depends on the definition used. Defining "left-behind" elders based on the observed migration of one child leads to a much higher incidence of "left-behind" cases than definitions that are elder-focused. The reason is simple: while every child of a migrant is left behind by that parent, many parents of migrants are not bereft of adult children with whom to live since the current generation of rural Chinese elders has, on average, four grown children plus their children's spouses as potential caregivers and companions. In addition, while there is widespread agreement that children need the care of parents, elder parents may not need the care of their adult children. Older adults choose from a menu of living arrangements. Even without migration not all Chinese rural elders would live with their children. Although evidence from the living arrangement literature for rural China shows a high rate of three-generation households before the Great Migration, the proportion was never close to 100 percent (Zeng and Wang 2004; Connelly, Maurer-Fazio, and Zhang, 2014). In considering this issue, we link the literature focused on migration and those left behind to the literature on the living arrangements of rural Chinese families, which have been largely separate literatures to this point.

In order to more accurately assess an elder's living arrangement we must differentiate between the family members registered officially as part of the household and those present, actually residing in the interview households. Using the household roster without accounting for migration undercounts the elders who are living alone or with spouse only. However, it is equally problematic to define elders are "left behind" simply because there is a migrant registered in their household. Comparing the living arrangements of elders with at least one migrant in the household and those without a migrant in the household we find little difference in living arrangements. Yes, those who have a migrant in their registered household are somewhat more likely to live alone, but they are just as likely to live with children or grandchildren. This result is fundamentally important in understanding why the analysis of the effect of migration on elders must be elder-centric not migrant child-centric.

Beginning with the simplest dichotomy, living with one's offspring (which can be children and/or grandchildren and may include one's spouse as well) we estimate a reduced-form probit regression focused on the individual characteristics of elders: number of sons and daughters, education, health, gender, widowhood status, education and age. We find strong effects of widowhood, age, and ability to work. From this descriptive model, we settle on three categories of living arrangements, alone, with spouse only, and with offspring. While these three categories constitute very different realities for the elders, they should be easy to establish in most data sets and thus contribute to meaningful comparative research. Cross tabulations of these categories with individual demographic information reveal expected patterns: the proportion of elders living alone decreases with age and poor health. The proportion living with spouse only is highest for the group of elders who still working. 
To understand the impact of migration on living arrangements more fully, we expand the categories of living arrangements to consider elders' residence in relationship to their other children in the village. Many of the elders who live alone or with spouse only have children living in the same village. These elders are not "at risk" in terms of lack of caregiving potential in the same way as elders living alone or with spouse only with no children in the same village. Finally, we differentiate between elders living with adult children (perhaps in conjunction with grandchildren) versus those living with grandchildren without the middle generation. This latter group is also a cause for concern in the migration literature, "at risk" in a different way with substantial burdens of child care and farming and less resources for their own care if care should be needed.

Beyond our careful accounting of the rural elders living arrangements in light of the migration of their adult children, we consider some possible consequences of living alone or with spouse only in terms of employment and psychological outlook and life satisfaction. These latter analyses, like the others in this paper, are agnostic on causal direction. Migration of adult children has the potential to affect elders' decision making and well-being, but it is equally likely that the migration decisions of adult children are affected by family circumstances including the exogeneous health status of living parents and parents-in-law, a direction of causation explored by Antmann (2012, 2013), Démurger and Xu (2015), Giles and Mu (2007), and Stohr (2015). The causal direction is strongly influenced by the age of the elder. Younger and relatively healthy elders enable the migration decisions of their offspring by acting as caregivers of their grandchildren and maintainers of the family's land allocation while those of advanced age or in frail health may deter the migration of offspring (Giles and Mu 2007). With both pathways of causality potentially strong we opt instead for a descriptive analysis of the situation on the ground. Who is home, who is away? In rural China, who do elders live with and among in the era of the Great Migration and how do these groups differ in their probabilities of employment and measures of well-being?

\section{II: RUMiC Rural Data}

The ongoing RUMiC project's goal is to collect information on the causes and consequences of migration in modern China (Meng, 2010; Akgüç, Giulietti, and Zimmermann, 2014). As such, data have been collected in rural areas to gather information on rural residents and in urban areas to gather responses from both urban residents and rural-to-urban migrants. The rural resident surveys of 2008 and 2009 form the basis of our analysis. It was carried out by China's National Bureau of Statistics (NBS) and includes a random sample of 8000 rural households from 8 provinces (Jiangsu, Zhejiang, Guangdong, Hebei, Hubei, Anhui, Henan, and Sichuan) and 1 provincial-level municipality (Chongqing). The sample is based on the regular sampling frame employed by the NBS for its annual household income and expenditure surveys (Kong 2010), which includes everyone with a rural household registration. The resultant rural sample of the $\mathrm{RUMiC}$ project contains households with and without migrant members.

The household heads, or their spouses, supplied information on migrant and other household members not present at the time of the survey (Lee and Meng, 2010). The attrition rate between the 2008 and 2009 surveys was negligible, allowing us to also combine information from the 
2009 rural survey about the non-resident children of the resident parents of the household heads and spouses via the 2009 module on the siblings of the household heads and their spouses.

From this data we extract a sample of all the elders who reside in sampled rural households. These elders fall into two categories - those who were categorized by the enumerators as the household heads or the spouses of the household heads and those who were categorized as the parents or parents-in-law of the household heads. The distinction matters in terms of what information is available for them in the data set. However, we have chosen variables for our analysis that are available for all respondents. Together the heads of households, their spouses, and their resident parents constitute a random sample of all rural residents age 60 or older in the nine surveyed provinces.

It is well know that elders' living arrangements vary considerably with age (Zeng and Wang 2004, Lei et al 2011, Connelly, Maurer-Fazio, and Zhang 2014, Connelly et al 2015). The literature analyzing elders' well being has yet to standardize the age cutoff for investigation. We focus here on rural elders age 60 and above as after 60 employment and hours worked decline noticeably (Connelly and Maurer-Fazio, forthcoming, Connelly, Maurer-Fazio, and Zhang 2014). In addition, because of the increases in mortality that kick in at this age, many more people become widows or widowers after age 60 and widowhood demonstrably affects living arrangements in China (as it does most places) (Connelly et al 2015). The next section describes the sample of all persons age 60 or older in sampled households.

\section{III: Living Arrangements of All Elders in Sampled Households}

Of the 8,000 households of the RUMiC rural sample, 1,924 have at least one person age 60 and above, resulting in a sample of 3,562 elders. As introduced above, this sample is made up of two groups, those elders who are themselves heads of household or spouses of heads of household and the resident parents of the heads of household and spouses.

(Insert Table 1 here.)

As Table 1 reveals, these two groups of elders differ considerably by age. The larger group, the household heads and their spouses, are relatively young with a mean age of approximately 65 . The smaller, but still substantial, group of parents and parents-in-law of household heads have an average age of approximately 75 . It should be noted here that while all the household heads and spouses included in our elder sample are themselves 60 years old or older, the household heads of those identified as parents and parents-in-law of household heads include many younger household heads, that is, the requirement for inclusion in our analysis is simply that the parents themselves are age 60 or older. This explains the gap of only 10 years in the mean ages of the group of elder household heads and spouses and the group of elder parents and parents-in-law of household heads and/or their spouses.

The sample respondents who were enumerated as heads of household and spouses of heads of household are also more likely to be male. This result is partly a function of age, but is also the result of enumerators' decision rules in terms of who is designated the head of the household. However, by combining the older heads of household and spouses and the parents of the heads of 
household and spouses we have a complete accounting of all the elders residing in sampled households.

(Insert Table 2 here.)

Table 2 begins our exploration of the living arrangements of rural elders using information derived from the household record. We use the household ID to identify distinct households and then we count all those sharing a household ID. This strategy of using the household roster is employed by most empirical studies of living arrangements. In the first panel of Table 2, we present a three-way taxonomy of living arrangements based on household registration: those who live alone, those who live with their spouse only, and those who live with offspring (children or grandchildren) regardless of whether a spouse is also present. In contrast, in the second panel we base our calculations only the members of the household actually present, excluding those who are registered as part of the household, but in reality, are away as out-migrants. We classify household members as migrants if they lived away from the household for 6 months or more in 2007. ${ }^{1}$ Comparing the two panels, it is clear that for rural areas with substantial out-migration, it is important to exclude migrants from the household to get a genuine picture of the extent to which elders live alone or with their spouse only. Ignoring migration, it appears that only $26 \%$ are living alone or with spouse only. However, their share increases to $36 \%$ when the outmigration of other household members is appropriately taken into account. Thus, Table 2 provides a cautionary tale for those wishing to construct living arrangement taxonomies from Chinese survey data based on the National Bureau of Statistics' definition of households as consisting of registered household members. Because of the large out-migration of rural residents, the number registered household members often exceeds the number of people actually living in the household.

Are all of the elders who live alone or with their spouse "left-behind"? Table 3 indicates that this is not the case. Table 3 divides the sample into elders who have at least one adult child registered as residing in the same household who is a migrant and those with no adult children registered as residing in the same house who are migrants. Row 1 reveals that $28 \%$ of the sampled elders live in households with adult children who are migrants.

\section{[Insert Table 3 here.]}

Rows 2, 3 and 4 showcase the similarities and differences in the living arrangements of elders according to whether there is one or more migrant child included in the household rosters. As the third row indicates, the share of elders who live with their offspring is identical, regardless of whether the household includes migrants. The differences show up in the first two rows. The share of those living alone is somewhat higher in households with migrant children than in those without migrants. The share living with spouse alone is somewhat lower in households with migrants than those without.

\footnotetext{
${ }^{1}$ Our criterion for migrant status is more conservative than the 3 months away used by Lee and Meng (2010) because our focus is on the ability to care for those staying in rural areas instead of the migrant experience itself.
} 
Most other analysts (Biao, 2007; Luo, 2009; Tse, 2015; Ao, Jiang, and Zhao, 2015) have identified "left-behind" elders from the perspective of migrants. For example, Luo analyzes a sample of rural residents aged 54 to 91, who have at least one adult child migrated. Ao, Jiang and Zhao (2015) using the same RUMiC rural data analyze household heads and spouses aged 50 plus and count the number of adult children who have migrated. From this perspective, all the non-migrant household members of a migrant's household are left behind. If we applied that approach to our sample of elders in the sampled RUMiC rural households, it would lead to defining all 975 elders in column two of Table 3 as left-behind. But Table 3 clearly shows that 63 percent of the elders with a migrant adult child registered in the same house are still coresiding with other children and grandchildren. We are not inclined to think of these elders as left behind. In addition, the commonly employed and migrant-centric criteria of defining left-behind as those having any migrant child is even broader than the one we have defined here. To count an elder has having a migrant child; we require the migrated offspring to be registered in the same household as the elder. It is more than likely that many of the elders in column one have migrant children who are registered in other households in the village.

Part of the problem of defining elders at risk as those affected by the migration of one of their adult children is that the concept of "left-behind" was borrowed from analyses of children leftbehind. However, the situation of children and elders is not parallel. Defining dependent children as left-behind is straight-forward enough. Children are left behind if one or both parents migrate out for work. The direction of responsibility is simple for the parent and young child relationships. The parents are responsible for the well-being of their own children. However, it is erroneous to treat elders analogously with children, that is, to select and identify elders as left behind simply from the perspective of using the migrant as the unit of observation. Many of these supposedly "left-behind" parents are still relatively young, in their forties, fifties, or sixties; are healthy; and have agency. Many have participated family decisions involving migration. Relatively young parents of migrant adults often enable the migration of the one who migrates by providing care to grandchildren, farming their land, and helping out the "left-behind" spouses.

Elders live separately from their adult children for many reasons. Economic studies of living arrangements around the world have shown that privacy is a normal good, that is, those older people with higher incomes are more likely to live separately from their children, all else equal (Lei et al 2011, Meng and Luo 2008). Even when their children do not migrate, parents of adult children may choose to live independently. In addition, for elders who need care, it is possible that some their children live nearby instead of within the same household. Of course, it is also possible that other elders find themselves in need of care, yet living alone and vulnerable and without nearby offspring--not as a matter of choice and not in a desirable situation. Certainly members of this last group are worthy of the concern of policy-makers and of analysis by researchers interested in exploring the extent to which their situation is the result of migration.

(Insert Table 4 here.)

In Table 4 we explore differences in the distribution of living arrangements by some characteristics of the individuals. We began our assessment of elders' living arrangements by asserting that these vary tremendously with age. Table 4 demonstrates this variation clearly. The younger groups of elder parents, those in their 60 s are much less likely to live with their 
offspring (children and grandchildren) that are those age 70 and above. This change with age is, in part, related to widowhood, which is observed indirectly with the decline in living with spouse only. Interestingly, Table 4 also reveals that the proportion living alone increases after age 70, as does the proportion living with offspring.

Just as we expect age and widowhood to increase the probability that elders co-reside with their adult children, we also expect that poor health and frailty are positively correlated with elders living with their children. The RUMiC data contain two variables that we employ to signal the health of the sample's elders. The first is the elders' direct response to a question that asks them to report their health status relative to their peers. The responses vary along a 5-point scale from very poor to excellent. Table 4 reveals that $84 \%$ of the sample's elders report themselves to be in average or good health. It also reveals that those at the extremes, that is, those in very poor health and those in excellent health, both constituting small shares of our sample are, respectively, much less likely and much more likely to live independently of their offspring.

We also approach the relationship between elders' health and their living arrangements from a slightly different perspective. We exploit the survey question that addresses respondents' work status at the end 2007. One of the potential responses is that of having lost the capability to work. We use this response to indicate a measure of disability. As we see in Table 4, those who have lost the ability to work, and are in this sense disabled, are much more likely to live with their offspring than are those still able to work. Least likely to live with their children are those elders who are reported as working. We classify all those who are wage earners, farmers, selfemployed, or working in family businesses (even if unpaid) as working and the rest as not working. Those who are able to work, but are not working, are more likely to live with their children than those working, but less likely to live with their children than those who report they cannot work.

Of course, age, health, and working status are interrelated. In Table 5 we present the results of a probit model of the probability of living with one's offspring. The advantage of this model over Table 4 is that we can observe the marginal effects of demographic characteristics on the choice to live with one's children.

The included variables are gender, widowhood, education, health, disability to work, age, and the number of living sons and daughters. Age is entered as five-year age cohorts as age effects appear to be highly non-linear. Education is also entered in levels with illiteracy as the omitted category. Twenty-nine percent of the sample is in this category.

In column 2 we have added two variables, the number of sons and daughter living in the village, respectively. For parents of household heads this information was obtained from the 2009 module on the location of siblings of the household heads so there will be some measurement error from the implicit assumption that these 2009 locations of residence also apply to 2008. For the household heads and spouses themselves, the same information is obtained from a 2008 data module on all the children of the household head who are not co-residing. Since the number of sons and daughters also appears in the model, we can interpret the marginal effects of the number of sons and daughters in the village as the additional effect on living with one's offspring of having those sons and daughters living in the same village. 
The results in Table 5 corroborate each of the bivariate relationships shown in Table 4. Living with one's children is increasing likely as one ages, however the effect does not begin until age 70. Higher levels of education reduce the probability to co-residing. Being widowed increases the probability of co-residing by 11 percentage points and not being able to work increases the probability by almost 9 percentage points. It is noteworthy that self-reported overall health is not related to co-residence with one exception: those in good health are 4 percentage points more likely to co-reside with their offspring than those in average health. This result serves as a good reminder that co-residence may be for the purpose of helping the younger generation with household tasks and childcare. Also noteworthy in its lack of statistical significance is the indicator variable for gender. Although women are more likely to live with children than men, but the results in Table 5 indicate that this is because women live longer and are more likely to have lost their spouse than men.

The final set of variables in Table 5 count the number of adult sons and daughters still alive, and in column 2, the number of adult sons and daughters living in the same village as their parents. ${ }^{2}$ Because of long-standing son preference, patri-locality, and patterns of elder care by sons and daughters-in-law rather than daughters, we include number of sons and daughters separately. The results show that the number of sons matters substantially more than the number of daughters. In column 1, which does not include the location of residence of one's adult children, having more sons slightly reduces the probability of living with one's children. This finding may seem surprising until we remember that sons often provide monetary support for parents and that privacy is a normal good. In column 2 , we see this more clearly as the total number of sons reduces the probability of co-residence but the number of sons in the village increases the probability of co-residence. Combining these two results, the total effect of more sons in the village is an increased probability of co-residence with children. The effects for daughters have the same signs as sons but are much smaller. The mean number of sons in the village, 1.2, exceeds the mean number of daughters in the village, 0.37 , and provides evidence of the customary pattern of daughters marrying outside the village and going to live with or nearby their parents-in-law.

(Insert Table 6 here.)

In order to explore the extent of elders who are at risk, that is, lack proximity to potential family caregivers, in Table 6 we explore in more detail the living arrangements of those elders who live alone or with spouse only. Here we consider both the location of adult children in the village and whether the elders are living alone or as empty-nesters because household members have migrated away. Table 6 reveals that $69 \%$ of those living completely alone are alone due to the out migration of family member, while the other $31 \%$ are registered as living alone. They may not have had children, they may have outlived their children, they have chosen to live alone or their children may have migrated out long enough ago that the household registration has been changed. The proportion living with spouse only because of the migration of a registered

\footnotetext{
${ }^{2}$ Here adult child is defined as a child over age 16 to correspond to the information available in the RUMiC
} data on adult children living away from home. 
household member is much lower. Twenty-five percent of those co-residing only with their spouse are in that situation due to the out-migration of family members. The other $75 \%$ of spouse-only households are registered as spouse-only households.

We think it important to understand and acknowledge the proportion of those who are living alone or with a spouse only, regardless of whether it is because of migration, which has an adult child living in the same village. Row 2 of Table 6 provides this information. Of the elders living alone, $28 \%$ have children living in the village. Similarly, $54 \%$ of elders living with their spouse only have children living in the same village. We are certainly less concerned about these elders than the ones living alone or with spouse only who have no children in the village. Those without children in the village are the most vulnerable group, those for whom the lack of adult children nearby may prove critical to their health and wellbeing. Adding together the alone and spouseonly elders with no children in the village, we find that $17 \%$ of the total elder sample are "at risk" in this way and just less than half of them, $45 \%$, are in this living situation because of the migration of a household member. Seventeen percent is still substantial, but it is a much smaller share than the $28 \%$ with a migrant adult child.

(Insert Table 7 here.)

In Table 7, we further explore the living arrangements of elders who co-reside with their offspring (children and/or grandchildren). Table 7 shows that, of the elders who live offspring, $82 \%$, are living with their adult children (there may also be grandchildren present), while $18 \%$ live with their grandchildren with a missing middle generation. Of those elders who co-reside with their grandchildren, the vast majority of cases, regardless of whether the elders have other children in the village, are due to the out-migration of the elder's adult children, the grandchildren's parents.

We may want to add those elders living with grandchildren only without other children in the village into the "at-risk" group though our concerns about them are quite different from those living alone or with spouse only. Those living with grandchildren with a missing middle generation may receive both help and companionship from the grandchildren, but they are also shouldering a substantial amount of responsibility and may be under more stress than they would be if the children's parents were around.

\section{IV: "Consequences" of Living Arrangements -- The Relationship of Work and Living Arrangements}

As mentioned above, we classify all those who are wage earners, farmers, self-employed, or working in family businesses (even if unpaid) as working and the rest as not working. In this section of the paper we explore how elder's proclivity to continue to work is related to their living arrangements and a number of demographic factors such as age, gender, education, and reported health. Controlling demographic factors, are elders who live alone or with spouse only more likely to work than those who live with their adult children? In Table 8 Models 1, 2, and 3 we report the marginal effects of these demographic factors on whether elders work, based on 
probit regressions. The models differ only in the detail of the living arrangements. Model 1 includes the simple 3-way classification of living arrangements that is available in most data sources, that is, elders who live alone, with spouse only, or with their adult children and possibly their spouse. In Model 2 we compare results based on a 6-way classification of living arrangements that distinguishes between those with and without children in the village. For those living with offspring we distinguish between those with or without a spouse is present. In Model 3, we further expand the classification of offspring to isolate the situation where elders may be living with grandchildren without the presence of their children, the grandchildren's parents, while at the same time maintaining the information on the presence of other children in the village. We use the traditional Confucian ideal of living with one's spouse and offspring as the base case and report the marginal effects for those who live in various arrangements without their offspring. Note that the definition of the base case changes subtly across the columns since in Model 1 it is living with any offspring, in Model 2 it is living with any offspring and one's spouse, and in Model 3 it is living with one's children and spouse.

(Insert Table 8 here.)

Consider first the living arrangement results for Model 1. Elders who are living with their spouse only are percentage points more likely to work than those who live with their offspring. Interestingly, in Model 1 there is no significant difference in the proclivity to work between those living alone and those living with offspring.

A comparison of these results with those from Models 2 and 3, reveals that elders living with their spouses alone, whether or not they have children in the same village, are significantly more likely to be working than both those living alone (regardless of whether they have children in the village) and those living with both their spouse and their adult children. Those living with their adult children without a spouse present, a situation largely attributable to widowhood are 12 percentage points less likely to work than those living with their spouses and children.

In Model 3 we find that three of the four groups of elders who live with their grandchildren while the grandchildren's parents are absent are much more likely to be working: elders with no spouse present (mainly widows and widowers) who are living with grandchildren alone with no children residing in the same village and those with a spouse present living with grandchildren whether or not the elders have other children in the village. Each of these groups is at least 20 percentage points more likely to be working than those who live together with their spouses and adult children. In the fourth case, that of elders living with grandchildren with no spouse present yet with other children in the village, we have too few observations (only 6 cases) to obtain statistical significance. The increase in the probability of working among grandparents caring for grandchildren without prime age adults present parallels findings, based on rural data, of Connelly, Maurer-Fazio, and Zhang 2014. ${ }^{3}$

The marginal effects of the other demographic variables are robust to the specificity of the living arrangement classification. As predicted, the probability of working declines with age, with those 65-69 about 10 percentage points less likely to be employed and those 70-74 about 20 percentage

${ }^{3}$ Connelly, Maurer-Fazio, and Zhang 2014 used a somewhat younger sample of elders aged 50 to 74 since they focused, primary, on employment decision making. 
points less likely to be employed than those 60-64. The big break comes at age 75 to 79 when elders of this age are approximately 40 percentage points less likely to be employed than the youngest included age cohort. We also observe that women are significantly less likely to work than men. Both these results are similar to the rural results of Connelly, Maurer-Fazio, and Zhang (2014), which was based on the 2000 Chinese Census.

We use illiteracy as the educational base case, given that a significant share of the elders is illiterate, and particularly so for the women. The two groups of elders who have attained primary or junior-high educations each have a 5 percentage point higher probability of working than those who are illiterate, while those with senior-high or better educations are 10 percentage points less likely to be working. We suspect that the elders in this more educated group were probably able to amass sufficient savings and wealth to better afford to retire or cease working.

As expected, for elders being in either very poor or poor health significantly lowers the probability of working-- very poor health more so than poor health. We use self-reported average health as the base case. Neither being in good or very good health changes the probability of working relative to those in average health.

\section{V: "Consequences" of Living Arrangements -- The Relationship Between Psychological Outlook and Living Arrangements}

The rural questionnaire of the RUMiC project asks household members present at the time of the interview a series of 12 questions about their feelings and outlook on life. Half of these questions are phrased positively and half phrased negatively. ${ }^{4}$ Each of the questions is answered on a 4point scale with the lower numbers indicating better feelings and positive psychological outlook and higher numbers indicating worse feelings and negative outlook. We summed each respondent's answers to these 12 questions to get a 36-point outlook variable that varies between 12 and 48. We used this composite outlook variable as the dependent variable in a set of three regressions presented in Table 9. Each of these models varies from the previous only in terms of the complexity of the classification of living arrangements. We use the same set of living arrangement classifications as in section IV. In each of these regressions we also control for age, education, health, ability to work, and gender.

In each of these 12 outlook questions, a larger number (4 compared to 3 ) always indicates a worse outlook. Therefore a significant positive coefficient in Table 9 indicates a more negative outlook. Similarly, a significant negative coefficient indicates a more positive psychological outlook on the part of the elder. Looking across all three models of Table 9, we observe that living alone has a substantial negative effect (positive coefficient) on elders' psychological wellbeing whether or not they have non co-resident children in the same village. This effect is somewhat exacerbated in the cases where the elders live alone and have no children in the same village. Living with one's spouse alone in comparison to the base case leads to somewhat more negative feelings but the effect is quantitatively much smaller than living alone. In Models 2 and

\footnotetext{
${ }^{4}$ For example, respondents are asked, "In the last few weeks has your ability to concentrate on whatever you are doing been better than usual, the same as usual, less than usual or much less than usual?" and "In the last few weeks have you been able to enjoy your normal day to day activities more so than usual, the same as usual, less so than usual, or much less than usual?"
} 
3, comparing the coefficient of living with one's spouse only with living with one's offspring without a spouse we find the loss of a spouse has a much larger negative effect on outlook than living without one's offspring. These results accord with those of Silverstein, Cong, and $\mathrm{Li}$ (2006).

In Model 3, we again explore the effects of living with grandchildren whose parents are absent. In the first two cases, those with no spouse but grandchildren without and with other children in the same village, there are very few observations and the coefficients are insignificant. In the last two cases where spouses are present along with grandchildren whose parents are absent, there are plenty of observations. The two coefficients on categories involving grandparents (with spouses present) living with their grandchildren suggest, in the first instance when the grandparents have no other adult children living in the same village, that their outlook on life is not significantly different from the case of elders living in the more traditionally ideal situation with their spouse and own children. And in the second instance, when the grandparents (with spouses present) living with their grandchildren have other children in the same village, the coefficient suggests the elders' outlook is somewhat more negative than in the ideal set up but not as negative as those without spouses but with children. Overall, we comes away with the sense that the presence of elders' spouses is the key factor in their psychological wellbeing, more important than the presence of elders' adult children. ${ }^{5}$ Social science researchers have, up to this point in time, focused more on the absence of adult children than on the debilitating effect of the loss of one's spouse. Losing one's spouse appears to change one's role in the family. Elders are more likely to live with children, less likely to work, and more likely to be depressed controlling for age, gender and health. This finding has important implications for considering who is at risk and vulnerable amongst China's rural population of elders.

(Insert Table 9 here.)

In terms of the demographic factors, we see that in each model age has a negative effect on outlook after age 75 and, in each model, women have a considerably more negative outlook than men. ${ }^{6}$ Education has a monotonically positive effect on outlook. ${ }^{7}$ Not unexpectedly, health also plays a big role in elders' outlook on life. Those in poor health are much more negative in their outlook than those with average health. Similarly, those in good health are much more upbeat in their perspective on life. These health effects are significant even with the inclusion of the indicator of the inability to work which is shown to have its own negative effect on outlook.

\section{VI: Conclusions}

In many places around the world, large numbers of prime-working-age adults leave their traditional family homes and migrate to urban areas in search of work. In many instances they leave behind close relatives including children, spouses, and parents. In China the situation is exacerbated by a set of laws and regulations that both make family migration difficult and

\footnotetext{
5 This result on widowhood is similar to the findings of Zhou et al (2015).

${ }^{6}$ Qin, Wang, and Hsieh (2015) also find similar effects of age, gender, and education on mental health in China, based on a nationally representative data set.

${ }^{7}$ Strauss et al (2010) and Smith, Strauss, and Zhao (2014) also find a positive effect of education on mental and physical health outcomes using the CHARLS pilot sample.
} 
provide incentives to keep a family's hands in agriculture. Even when the benefits of migration outweigh the costs, the costs may be quite high and are inherently borne by the more vulnerable members of society, that is, children and elders. This paper is focused on China's rural elders residing in areas that have experienced large migrant out flows of the prime-age population.

In the 2008 RUMiC rural sample, 28 percent of the elders live in a household which includes an adult child (over 19) who was away from the household for six or more months the previous year. A migrant-centric measure of "left-behind" elders would classify all these elders as "left behind". However, we have demonstrated that the distribution of the living arrangements of elders with migrant adult children is very similar to that of the living arrangements of those without migrant adult children. We use this illustrative result to urge that analysis of "leftbehind" elders relocate its focus from the migrant as the unit of analysis to the elder as the unit of analysis. The elder-centric analysis we favor also takes into account the ultimate sources of welfare concern and suggests that specific groups of elders are affected by migration in differing ways.

One group of adult-stayers is affected by the Chinese migration pattern of leaving young children at home. These elders are relatively young. They are able to care for the grandchildren and "hold down the fort" in terms of farming and other cottage industries of their households. We found that they are much more likely to be working, to still have a living spouse, and to express levels of well-being only somewhat lower with those living with both spouse and children (and grandchildren).

An older group of adult-stayers affected by migration consists of those living alone or with their spouse only. Sixty-eight percent of those who are living alone are alone because of the migration of a household member compared with $25 \%$ of those living with spouse only. Those living alone without children in the village appear to be the most at risk; they have low levels of employment and significantly lower measures of well-being than those living with their spouse only. However, this group, those that the term "left-behind" evokes, represents just two percent of the elders' sample. The much larger group, that living with spouses only, has higher rates of working and only somewhat lower measures of wellbeing than those living with spouse and children. Overall, those living with spouses only appear better off than those living with their children but no spouse. (In most of these cases the spouse has died, but in a small number of cases the spouse is an out-migrant).

One of our key conclusions is that analysts need to be careful in translating concerns about leftbehind children to left-behind parents. Parents continue to have some agency in, and influence on, the migration decisions of the prime-age population. Current elders have multiple children who can act as caregivers when necessary. Conditions less under an elder's control such as becoming a widow/widower or becoming disabled and unable to work appear to be more life changing than the migration of the elder's children. Of course, more choice is better than less, such that removal of the barriers to family migration should improve the lives of Chinese rural elders. Fewer elders would be left in the solo care of their grandchildren and long-term rural-tourban migrants could move infirm/frail parents to the urban areas if need be. 
Finally, we remind readers that time is not on the side of Chinese elders. The lower fertility rates of the next generation to become elders imply more holes in the social safety nets of rural areas. We predict that the number and share of elders who find themselves "alone with no children in the village" will increase over the next twenty years. 


\section{References}

Akgüç, Mehtap, Corrado Giulietti, and Klaus F. Zimmermann. 2014. "The RUMiC longitudinal survey: fostering research on labor markets in China." IZA Journal of Labor \& Development 3 (1):1-14. doi: 10.1186/2193-9020-3-5.

Antman, Francisca M. 2012. "Elderly care and intrafamily resource allocation when children migrate." Journal of Human Resources 47 (2):331-363. doi:

10.1353/jhr.2012.0011.

Antman, Francisca M. 2013. "16 The impact of migration on family left behind." International Handbook on the Economics of Migration:293.

Ao, Xiang, Dawei Jiang, and Zhong Zhao. 2015. "The impact of rural urban migration on the health of left-behind parents." Working Paper.

Biao, Xiang. 2007. "How far are the left-behind left behind? A preliminary study in rural China." Population, Space and Place 13 (3):179-191. doi: 10.1002/psp.437.

Biavaschi, Costanza, Corrado Giulietti, and Klaus F. Zimmermann. "Sibling Influence on the Human Capital of the Left Behind." (2013).

Cai, Fang and Wang Dewen. 2006. "Impacts of internal migration on economic growth and urban development in China." Working Paper.

Chan, Kam Wing. 2012. "Migration and development in China: Trends, geography and current issues." Migration and Development 1 (2):187-205.

Chan, K.W. and L. Zhang, (1999), 'The hukou system and rural-urban migration in China: Processes and changes', The China Quarterly 160, 818-55.

Chang, Hongqin, Xiao-yuan Dong, and Fiona MacPhail. 2011. "Labor migration and time use patterns of the left-behind children and elderly in rural China." World Development 39 (12):2199-2210. doi: 10.1016/j.worlddev.2011.05.021.

Chen, Sheying, and Jason L. Powell. 2012. Aging in China: implications to social policy of a changing economic state. New York; London: Springer.

Cong, Zhen, and Merril Silverstein. 2008. "Intergenerational Support and Depression among Elders in Rural China: Do Daughters-in-Law Matter?" Journal of Marriage and Family 70 (3):599-612. doi: 10.1111/j.1741-3737.2008.00508.x.

Connelly, Rachel, Michael Iannotti, Margaret Maurer-Fazio, and Dandan Zhang. 2015. "Coresidency, Ethnicity, and Happiness of China's Rural Elders." Eurasian Geography and Economics. doi: 10.1080/15387216.2015.1058174. 
Connelly, Rachel and Margaret Maurer-Fazio. Forthcoming. "Labor Force Participation and Hours of Work of Western China's Rural Elders."

Connelly, Rachel, Margaret Maurer-Fazio and Dandan Zhang. 2014. "Labor Force Participation of Chinese's Population Aged 50 or Older from 1982 to 2000: What Role Does Coresidency Play?" IZA Working Paper 8068.

Connelly, Rachel, Kenneth Roberts, and Zhenzhen Zheng. 2011. "The settlement of rural migrants in urban China: some of China's migrants are not "floating" anymore." Journal of Chinese economic and business studies 9 (3):283-300. doi:

10.1080/14765284.2011.592356.

Connelly, Rachel, Kenneth Roberts, and Zhenzhen Zheng. 2012. "The role of children in the migration decisions of rural Chinese women." Journal of Contemporary China 21 (73):93111.

Démurger, Sylvie, and Hui Xu. 2015. "Left-behind children and return migration in China." IZA Journal of Migration 4 (1):1-21. doi: 10.1186/s40176-015-0035-x.

Du, P, Z Ding, Q Li, and J Gui. 2004. "The impact of out labor migration on the elderly stayers in rural areas." Population Research 28 (6):44-52.

Fan, C. (1999), 'Migration in a socialist transitional economy: Heterogeneity, socioeconomic and spatial characteristics of migrants in China and Guangdong province', International Migration Review, 33 (4), 954-87.

Gao, Yang, Li Ping Li, Jean Hee Kim, Nathan Congdon, Joseph Lau, and Sian Griffiths. 2010. "The impact of parental migration on health status and health behaviours among left behind adolescent school children in China." BMC public health 10 (1):56-56. doi: 10.1186/1471-2458-10-56.

Giles, John, and Ren Mu. 2007. "Elderly parent health and migration decisions of adult children: evidence from rural China." Demography 44 (2):265-288. doi:

10.1353/dem.2007.0010.

Giles, John, Dewen Wang, and Changbao Zhao. 2010. "Can China's Rural Elderly Count on Support from Adult Children? Implications of Rural-to-Urban Migration." Journal of Population Ageing 3 (3):183-204. doi: 10.1007/s12062-011-9036-6.

Guo, M. A. N., Maria P. Aranda, and Merril Silverstein. 2009. "The impact of out-migration on the inter-generational support and psychological wellbeing of older adults in rural China." Ageing and Society 29 (7):1085-1104. doi: 10.1017/S0144686X0900871X.

Hare, Denise. 1999. "Push" versus "pull" factors in migration outflows and returns: determinants of migration status and spell duration among China's rural population." The 
journal of development studies 35 (3):45-72. doi: 10.1080/00220389908422573.

Jacka, Tamara. 2012. "Migration, householding and the well-being of left-behind women in rural Ningxia." China Journal, The (67):1-21.

Kong, Sherry Tao. 2010. "Rural-urban migration in China: survey design and implementation." in Meng, X., Manning, C., with Li, S., Effendi, T.(Eds.), The Great Migration: Rural-Urban Migration in China and Indonesia. Edward Elgar Publishing Ltd::135-150.

Lee, Leng, and Xin Meng. 2010. "Why don't more Chinese migrate from the countryside? Institutional constraints and the migration decision." in Meng, X., Manning, C., with Li, S., Effendi, T.(Eds.), The Great Migration: Rural-Urban Migration in China and Indonesia. Edward Elgar Publishing Ltd.:23-45

Lei, Xiaoyan, John Strauss, Meng Tian, and Yaohui Zhao. 2011. "Living Arrangements of the Elderly in China: Evidence from CHARLS." IZA Institute Discussion Paper No. 6249.

Liang, Zai. 2007. "Internal Migration: Policy Changes, Recent Trends, and New Challenges 1." In Transition and Challenge: China's Population at the Beginning of the 21st Century, edited by Zhongwei Zhao and Fei Guo. Oxford: Oxford University Press.

Liang, Zai, and Yiu Por Chen. 2007. "The educational consequences of migration for children in China." Social science research 36 (1):28-47. doi:

10.1016/j.ssresearch.2005.09.003.

Liang, Zai, Lin Guo, and Chengrong Duan. 2008. "Migration and the well-being of children in China." The Yale-China Health Journal 5:25-46.

Luo, Baozhen. 2009. The Impact of Rural-Urban Migration on Familial Elder Care in Rural China, dissertation.

Meng, Xin, and Chuliang Luo. 2008. "What Determines Living Arrangements of the Elderly in Urban China." In Bjorn Gustafsson, Shi Li and Terry Sicular (eds.), Inequality and Public Policy. Cambridge, MA: Cambridge University Press, 267-286.

Meng, Xin, and Chris Manning. 2010. "The great migration in China and Indonesia: trends and institutions." in Meng, X., Manning, C., with Li, S., Effendi, T.(Eds.), The Great Migration: Rural-Urban Migration in China and Indonesia. Edward Elgar Publishing Ltd.:1-22.

Meng, X., Manning, C., with Li, S., Effendi, T.(Eds.). 2010. The Great Migration: Rural-Urban Migration in China and Indonesia. Edward Elgar Publishing Ltd

Mu, Ren, and Dominique Van de Walle. 2011. "Left behind to farm?: women's labor reallocation in rural China." Labour economics 18 (1):83-97. doi:

10.1016/j.labeco.2011.01.009. 
Qin, Xuezheng, Suyin Wang, and Chee-Ruey Hsieh. 2015. "The prevalence of depression and depressive symptoms among adults in china: estimation based on a national household survey." Conference paper presented at the First World Congress of Comparative Economics, June 26, 2015, Rome.

Roberts, Kenneth, Rachel Connelly, Zhenming Xie, and Zhenzhen Zheng. 2004. "Patterns of Temporary Labor Migration of Rural Women from Anhui and Sichuan." The China Journal (52):49-70.

Silverstein, Merril, Zhen Cong, and Shuzhuo Li. 2006. "Intergenerational transfers and living arrangements of older people in rural China: Consequences for psychological wellbeing." The Journals of Gerontology Series B: Psychological Sciences and Social Sciences 61 (5):S256-S266.

Smith, James P., John Strauss, and Yaohui Zhao. 2014. "Healthy aging in China." The Journal of the Economics of Ageing 4:37-43. doi: 10.1016/j.jeoa.2014.08.006.

Stöhr, Tobias. 2015. "Siblings' interaction in migration decisions: who provides for the elderly left behind?" Journal of Population Economics 28 (3):593-629. doi: 10.1007/s00148015-0546-z.

Strauss, John, Xiaoyan Lei, Albert Park, Yan Shen, James P. Smith, Zhe Yang, and Yaohui Zhao. 2010. "Health Outcomes and Socio-economic Status Among the Elderly in China: Evidence from the CHARLS Pilot." Journal of Population Ageing 3 (3):111-142. doi: 10.1007/s12062-011-9033-9.

Wang, Sophie Xuefei. 2014. "The effect of parental migration on the educational attainment of their left-behind children in rural China." The B.E.journal of economic analysis \& policy 14 (3):1037-1080. doi: 10.1515/bejeap-2013-0067.

Zeng, Yi and Zhengdian Wang. 2004. "Family and Changes of Living Arrangements of the Elderly in China," Chinese Journal of Population Science. No. 5, October 1, pp.2-8.(in Chinese)

Zhou, Yicheng, Linyi Zhou, Changluan Fu, You Wang, Qingle Liu, Hongtao Wu, Rongjun Zhang, and Linfeng Zheng. 2015. "Socio-economic factors related with the subjective wellbeing of the rural elderly people living independently in China." International journal for equity in health 14 (1):1-9. doi: 10.1186/s12939-015-0136-4. 
Table 1: Types of Elders, Age 60 and Older, in RUMiC Rural Sample Households

\begin{tabular}{|c|c|c|c|c|c|}
\hline & Frequency & Percent & $\begin{array}{l}\text { Mean } \\
\text { Age }\end{array}$ & $\begin{array}{l}\text { Percent } \\
\text { Female }\end{array}$ & $\begin{array}{c}\text { Number } \\
\text { of } \\
\text { Children } \\
\text { Ever } \\
\text { Born }\end{array}$ \\
\hline $\begin{array}{l}\text { Resident Parent or Parent-in-law of Household } \\
\text { Heads } \\
\text { Household Heads and Spouses of Household } \\
\text { Heads }\end{array}$ & 1,102 & 69.1 & 74.5 & 64.1 & 3.7 \\
\hline Total & 3,562 & 100 & 67.8 & 47.1 & 3.3 \\
\hline
\end{tabular}

Table 2: Living Arrangements of Elders in Rural Sample Households

\begin{tabular}{|l|cc|cc|}
\hline & \multicolumn{2}{|c|}{$\begin{array}{c}\text { Based on Registered } \\
\text { Members of } \\
\text { Households }\end{array}$} & $\begin{array}{c}\text { Based on Resident, } \\
\text { Non-Migrant, } \\
\text { Members of } \\
\text { Households Only }\end{array}$ \\
\hline Alone & Frequency Percent & Frequency & Percent \\
Only with spouse & 28 & 0.8 & 90 & 2.5 \\
With offspring (with or without spouse) & 894 & 25.1 & 1,198 & 33.7 \\
Registered Elder Not in House & 2,634 & 74.1 & 2,221 & 62.4 \\
Total & NA & NA & 50 & 1.4 \\
& 3,556 & 100 & 3,559 & 100 \\
\hline
\end{tabular}

Table 3: Living Arrangements of Elders in Sampled Households by Migration Status of Their Household's Adult Children

\begin{tabular}{|l|c|c|}
\hline & $\begin{array}{c}\text { No adult children } \\
\text { on household } \\
\text { roster are migrants }\end{array}$ & $\begin{array}{c}\text { One or more adult } \\
\text { child on household } \\
\text { roster is a migrant }\end{array}$ \\
\hline Percent of sample in category & $72 \%$ & $28 \%$ \\
\hline Living Arrangements & $1.38 \%$ & $5.95 \%$ \\
Alone & $35.47 \%$ & $30.56 \%$ \\
Only with spouse & $63.15 \%$ & $63.49 \%$ \\
With offspring (w or w/o spouse) & $100 \%$ & $100 \%$ \\
Total & & \\
\hline
\end{tabular}

Note: Adult children are defined as those age 20 and older. 
Table 4: Living Arrangements of Elders by Individual Characteristics

\begin{tabular}{|c|c|c|c|c|c|}
\hline Total & $\begin{array}{c}\text { Alone } \\
2.56\end{array}$ & $\begin{array}{c}\text { With } \\
\text { Spouse } \\
\text { Only } \\
34.14\end{array}$ & $\begin{array}{l}\text { With } \\
\text { Offspring } \\
\text { (with or } \\
\text { without } \\
\text { Spouse) } \\
63.29\end{array}$ & $\begin{array}{c}\text { Total } \\
100\end{array}$ & $\begin{array}{c}\% \text { of } \\
\text { sample } \\
100\end{array}$ \\
\hline \multicolumn{6}{|l|}{ Age Cohorts } \\
\hline $60-64$ & 2.39 & 43.44 & 54.17 & 100 & 45.52 \\
\hline $65-69$ & 2.53 & 41.79 & 55.68 & 100 & 22.67 \\
\hline $70-74$ & 5.15 & 28.64 & 66.22 & 100 & 12.67 \\
\hline $75-79$ & 2.26 & 12.58 & 85.16 & 100 & 8.77 \\
\hline 80 Plus & 0.54 & 2.18 & 97.28 & 100 & 10.37 \\
\hline \multicolumn{6}{|l|}{ Self Reported Health Status } \\
\hline Very Poor & 2.44 & 21.14 & 76.42 & 100 & 3.48 \\
\hline Poor & 1.81 & 32.51 & 65.69 & 100 & 12.64 \\
\hline Average & 3.15 & 32.88 & 63.97 & 100 & 39.87 \\
\hline Good & 2.46 & 35.71 & 61.83 & 100 & 35.8 \\
\hline Excellent & 1.41 & 41.55 & 57.04 & 100 & 8.2 \\
\hline \multicolumn{6}{|l|}{ Ability to Work } \\
\hline Unable to work & 2.3 & 13.65 & 84.05 & 100 & 19.67 \\
\hline \multicolumn{6}{|l|}{ Work Status } \\
\hline Working & 2.91 & 42.56 & 54.54 & 100 & 57.04 \\
\hline Able to work but not working & 1.96 & 31.05 & 66.99 & 100 & 23.29 \\
\hline
\end{tabular}

* Table excludes elder migrants 
Table 5 Probit Analysis of Elders' Probability of Living with their Offspring

\begin{tabular}{|c|c|c|c|c|c|}
\hline Explanatory Variables & $d y / d x$ & Sig. & $d y / d x$ & Sig. & Means \\
\hline \multicolumn{6}{|l|}{ Age Cohorts } \\
\hline $60-64$ & & & & & 0.46 \\
\hline $65-69$ & 0.013 & & 0.015 & & 0.23 \\
\hline $70-74$ & 0.062 & $* *$ & 0.069 & $* * *$ & 0.13 \\
\hline $75-79$ & 0.215 & $* * *$ & 0.222 & $* * *$ & 0.08 \\
\hline 80 Plus & 0.357 & $* * *$ & 0.367 & $* * *$ & 0.10 \\
\hline \multicolumn{6}{|l|}{ Education } \\
\hline Illiterate, base case & & & & & 0.29 \\
\hline Primary & -0.023 & & -0.018 & & 0.46 \\
\hline Junior High & -0.085 & $* * *$ & -0.069 & $* * *$ & 0.20 \\
\hline Senior High \& Above & -0.088 & $* *$ & -0.068 & $*$ & 0.05 \\
\hline \multicolumn{6}{|l|}{ Health } \\
\hline Very Poor & 0.013 & & 0.018 & & 0.03 \\
\hline Poor & -0.042 & & -0.029 & & 0.13 \\
\hline Average, base case & & & & & 0.40 \\
\hline Good & 0.043 & $* *$ & 0.044 & $* * *$ & 0.36 \\
\hline Very Good & 0.008 & & 0.010 & & 0.08 \\
\hline \multicolumn{6}{|l|}{ Ability to Work } \\
\hline Unable to work & 0.097 & $* * *$ & 0.088 & $* * *$ & 0.19 \\
\hline \multicolumn{6}{|l|}{ Marital Status } \\
\hline Widowed & 0.167 & $* * *$ & 0.111 & $* * *$ & 0.17 \\
\hline \multicolumn{6}{|l|}{ Gender } \\
\hline Female & 0.008 & & 0.014 & & 0.47 \\
\hline \multicolumn{6}{|l|}{ Number of Children } \\
\hline No. of Sons & -0.021 & $* * *$ & -0.125 & $* * *$ & 1.59 \\
\hline No. of Daughters & -0.006 & & -0.013 & $*$ & 1.29 \\
\hline No. of Sons in village & & & 0.167 & $* * *$ & 1.22 \\
\hline No. of Daughters in village & & & 0.032 & $* *$ & 0.37 \\
\hline Number of Observations & 3,434 & & 3,434 & & 3,434 \\
\hline
\end{tabular}


Table 6: Details of Living Arrangements Of Elders Living "Alone" or with "Spouse Only"

\begin{tabular}{|l|llc|}
\hline 1 & \multicolumn{1}{|l}{$\begin{array}{c}\text { Spouse } \\
\text { Only }\end{array}$} \\
2 & $\begin{array}{l}\text { Share of elders in this living arrangement due to out-migration of } \\
\text { household members }\end{array}$ & $68.9 \%$ & $25.2 \%$ \\
3 & $\begin{array}{l}\text { Share of elders in this living arrangement with no children in village } \\
\text { Share of elders in this living arrangement with no children in village who } \\
\text { are in this situation due to out-migration of household's children }\end{array}$ & $72.2 \%$ & $46.2 \%$ \\
\hline
\end{tabular}

Table 7: Details of Living Arrangements of Elders Living "With Offspring"

\begin{tabular}{|lr|}
\hline Live with children (with or without spouse, with or without grandchildren) & $81.8 \%$ \\
Live with grandchildren (with or without spouse) no children in village & $12.7 \%$ \\
Live with grandchildren (with or without spouse) with children in village & $5.5 \%$ \\
Total who live "with offspring" & $100.0 \%$ \\
& \\
$\begin{array}{l}\text { Percent co-residing with grandchildren without children in village because } \\
\text { of children's out-migration }\end{array}$ & $86.5 \%$ \\
$\begin{array}{l}\text { Percent co-residing with grandchildren, but with children in village because } \\
\text { of children's out-migration }\end{array}$ & $71.5 \%$ \\
\hline
\end{tabular}

